\title{
Paeonia lactiflora Extract Attenuating Cerebral Ischemia and Arterial Intimal Hyperplasia Is Mediated by Paeoniflorin via Modulation of VSMC Migration and Ras/MEK/ERK Signaling Pathway
}

\author{
Yuh-Fung Chen, ${ }^{1,2}$ Kuo-Jen Wu, ${ }^{1}$ and W. Gibson Wood ${ }^{3}$ \\ ${ }^{1}$ Department of Pharmacology, China Medical University, No. 91 Hsueh-Shih Road, Taichung 40402, Taiwan \\ ${ }^{2}$ Department of Pharmacy, China Medical University Hospital, No. 2 Yu-Der Road, Taichung 40447, Taiwan \\ ${ }^{3}$ Department of Pharmacology, University of Minnesota and Geriatric Research, Education and Clinical Center, \\ VA Medical Center, Minneapolis, MN 55455, USA
}

Correspondence should be addressed to Yuh-Fung Chen; yfchen@mail.cmu.edu.tw

Received 14 March 2013; Revised 10 May 2013; Accepted 15 May 2013

Academic Editor: Wen Chuan Lin

Copyright (C) 2013 Yuh-Fung Chen et al. This is an open access article distributed under the Creative Commons Attribution License, which permits unrestricted use, distribution, and reproduction in any medium, provided the original work is properly cited.

\begin{abstract}
Paeonia lactiflora is a well-known traditional Chinese medicine. Paeoniflorin is an active component found in Paeonia lactiflora which is used to treat smooth muscle spasms and pain and to protect the cardiovascular system. The objective of this study was to determine if Paeonia lactiflora would be protective in rodent models of cerebral ischemia and arterial intimal hyperplasia. Paeonia lactiflora extract (PLex) and paeoniflorin (PF) significantly attenuated cerebral infarction in ischemia/reperfusion injury rats and the severity of intimal hyperplasia in mice where the carotid artery was ligated. PLex and PF reduced PDGF-stimulated VSMC proliferation and migration in a dose-dependent manner by MTT, wound healing, and transwell assays. PF significantly reduced protein levels of Ras, MEK, p-MEK and p-ERK, but not MMP-2 and MMP-9. In summary, Paeonia lactiflora reduced cerebral ischemia and arterial intimal hyperplasia which were mainly made via the intermediary of PF. The protective effect of PF was related to the modulation of the Ras/MEK/ERK signaling pathway.
\end{abstract}

\section{Introduction}

Cerebral ischemia and infarction are most commonly associated with atherosclerotic disease and stroke in the carotid and vertebrobasilar circulatory systems [1]. Cerebral infarction and resulting pathology are a leading cause of disability and mortality. Restoration of blood flow is essential to prevent irreversible ischemic tissue injury. However, reperfusion can have local and systemic inflammatory effects that enhance tissue injury [2]. Abnormal proliferation and migration of VSMCs in arterial injury can lead to intimal hyperplasia [3-6]. The inability to limit intimal hyperplasia most likely relates to its complex nature, which involves inflammatory cells and their mediators, angiogenesis, and vascular smooth muscle cells (VSMC) growth and migration. There is a close relationship between vascular intimal hyperplasia and atherosclerosis, venous thrombosis, and balloon injury, which are a result of abnormal VSMC proliferation and migration $[7,8]$. Integrity of VSMC is required for optimal vascular function [9]. When the vascular endothelium is damaged, platelet-derived growth factor (PDGF) is released. PDGF stimulates cell growth and also promotes migration in VSMC and causes the development of intimal hyperplasia and restenosis [10-12]. Over the past decade, possible reperfusion injury has advanced understanding of pathophysiology. Cerebrovascular diseases can only be controlled by medication or surgery, but frequently patients relapse months or years later $[13,14]$. Therefore, discovering drugs that effectively attenuate ischemia-reperfusion (I/R) injury is a high priority.

Drugs that inhibit the activation of PDGF and VSMC proliferation and migration could be protective. 
Paeonia lactiflora Pall. (Ranunculaceae) is a well-known traditional Chinese herbal medicine which is used for relaxing abdominal spasm, relieving pain, and improving blood circulation. Paeonia lactiflora has been used as an antiallergic, anticonvulsant, anti-inflammatory, and antispasmodic herbal medicine. Paeoniflorin, a major component of Paeonia lactiflora has potent antispasmodic, anticoagulative, analgesic, and anti-inflammatory activities [15-17]. The biological effects of Paeonia lactiflora and PF on carotid vascular smooth muscle cells have not been explored. The objective of this study was to evaluate the effects of Paeonia lactiflora extract and paeoniflorin on cerebral ischemia/reperfusion injury and carotid-ligation artery in vivo, and PDGF-BB-stimulated vascular smooth cell (A7r5) migration in vitro.

\section{Materials and Methods}

2.1. Preparation of Plant Extract. Paeonia lactiflora Pall. was obtained from the Department of Pharmacy, China Medical University Hospital, Taiwan. Two kilograms of Paeonia lactiflora were extracted by using water $\left(100^{\circ} \mathrm{C}\right)$ for a $2 \mathrm{hr}$ cycle two times. The extract of Paeonia lactiflora (abbreviated as PLex) was collected, filtered, and frozen to a dry powder, and the yield was $8.23 \%$ of the total extract. PLex was freshly prepared in distilled water before experiments. HPLC-DAD (diode array detector) was used for the study of paeoniflorin (abbreviated as PF) in PLex. The HPLC-DAD conditions were based on an earlier report [18]. An HPLC chromatogram of PLex and PF is shown in Figure 1. The content of PF is $9.94 \mu \mathrm{g} / \mathrm{mL}$ in $2.5 \mathrm{mg} / \mathrm{mL}$ PLex.

2.2. Cell Line. A VSMCline, A7r5, was purchased from Bioresource Collection and Research Center, Hsinchu, Taiwan. A7r5 cells were plated onto 6-well plates in DMEM, supplemented with $10 \%$ FBS, 100 units/mL penicillin, $100 \mu \mathrm{g} / \mathrm{mL}$ streptomycin, and $2 \mathrm{mM} \mathrm{L-glutamine,} \mathrm{and} \mathrm{grown} \mathrm{at} 37^{\circ} \mathrm{C}$ under a humidified $5 \% \mathrm{CO}_{2}$ and $95 \%$ air at one atmosphere.

2.3. Chemicals. Chemicals were purchased from the following companies. PDGF-BB (PDGF) was from Sigma (St. Louis, MO, USA). Zoletil was from Virbac Laboratories (Carros, France). Anti-MMP-2, anti-MMP-9, anti-Ras, antiMEK, anti-phosphor-MEK1/2, anti-ERK, and anti-phosphoERK1/2 antibodies were from Abcam (Cambridge, UK). Anti- $\beta$-actin was from Santa Cruz Biotechnology (Santa Cruz, CA, USA). DMEM, FBS, penicillin/streptomycin, and glutamine were from Thermo Scientific Inc. (Waltham, PA, USA). 2,3,5-Triphenyltetrazolium chloride (TTC) was from Sigma-Aldrich (St. Louis, MO, USA). Paeoniflorin (PF) was purchased from IvyChemical Company (Cherry Hill, NJ, USA).

2.4. Animals. Male Sprague-Dawley (SD) rats, weighing 275$300 \mathrm{~g}$, and male ICR mice, weighing 25-30 g, were purchased from BioLASCO Co., Ltd. (Taipei City, Taiwan). All animals were fed with standard chow and housed in standard cages at a constant temperature of $22 \pm 1^{\circ} \mathrm{C}$. Relative humidity
$55 \% \pm 5 \%$ with $12 \mathrm{hr}$ inverted light-dark cycle for 1 week at least before the experiment. The experimental protocol was approved by the Committee on Animal Research, China Medical University (permit number: 101-251). All surgery was performed under zoletil anesthesia and all efforts were made to minimize suffering. The minimum number of animal required to obtain consistent data was used. Five to six animals were used in each group.

2.5. Surgical Procedures of Cerebral Ischemia/Reperfusion. Male SD rats were deeply anesthetized by intraperitoneal injection of $25 \mathrm{mg} / \mathrm{kg}$ of zoletil. The animal model of surgical cerebral infarction and ischemia/reperfusion were modified as described by Wu et al. [18]. Each rat was placed supine, and both common carotid arteries were exposed through a midline incision in the neck. Then, both common carotid arteries were tied off with plastic line $(0.1 \mathrm{~mm}$ in diameter). Distilled water and different concentrations of PLex $(50,100$, $200 \mathrm{mg} / \mathrm{kg})$ and PF $(0.5,1.0,2.0 \mathrm{mg} / \mathrm{kg})$ were orally administered $60 \mathrm{~min}$ before 3-vessels occlusion in rats, respectively. After $90 \mathrm{~min}$ occlusion followed by reperfusion for $24 \mathrm{hr}$, the brain of each rat was removed after transcardiac perfusion of $0.9 \% \mathrm{NaCl}$. Each brain was then placed into a plastic rat brain matrix and was sectioned coronally into $2 \mathrm{~mm}$ slices. The slices were stained with 2\% 2,3,5-triphenyltetrazolium (TTC) solution at room temperature for $15 \mathrm{~min}$. The slices were fixed with $10 \%$ formalin solution. The cerebral infarction areas of the first six sections from the frontal lobe were measured using an image-analysis system (Image-Pro Plus 6.0 Media Cybernetics, USA). The ratio of infarction area to total brain area in each section of the rat brain was calculated, and the data were expressed as a percentage (\%).

2.6. Animal Carotid Ligation Model. The carotid ligation model was modified from a previous report [19]. Male ICR mice weighing 25 to $30 \mathrm{~g}$ were used for the carotid-ligation model. All surgical procedures were performed with animals under general anesthesia (zoletil $25 \mathrm{mg} / \mathrm{kg}$, i.p.) using sterile surgical techniques with a dissecting microscope. A midline neck incision was used to expose the left common carotid artery. The artery was completely ligated just proximal to the carotid bifurcation. The right carotid artery served as a noninjured control. After ligation, the incision was closed, and the animals were allowed to recover. On the day of carotid ligation, mice were randomized into 3 treatment groups and they were anesthetized as described above. Group 1 was treated with distilled water and groups 2 and 3 were treated with PLex (100 and $200 \mathrm{mg} / \mathrm{kg}$ p.o.). PLex and distilled water were given by gastric gavages on the second day after carotid ligation once a day for 28 consecutive days. All animals were euthanized on day 29 after ligation for histomorphometric analysis. The left and right common carotid arteries were harvested, dehydrated in ethanol and xylene, and embedded in paraffin. Haematoxylin-eosin staining and PCNA antibody staining were used for the carotid arteries [19]. Arterial sections $(2.5 \mu \mathrm{m})$ were selected and stained by use of a haematoxylin-eosin solution. Images were digitized and analyzed with Image-Pro software. The areas of the lumen, internal elastic lamina (IEL), and external elastic lamina 


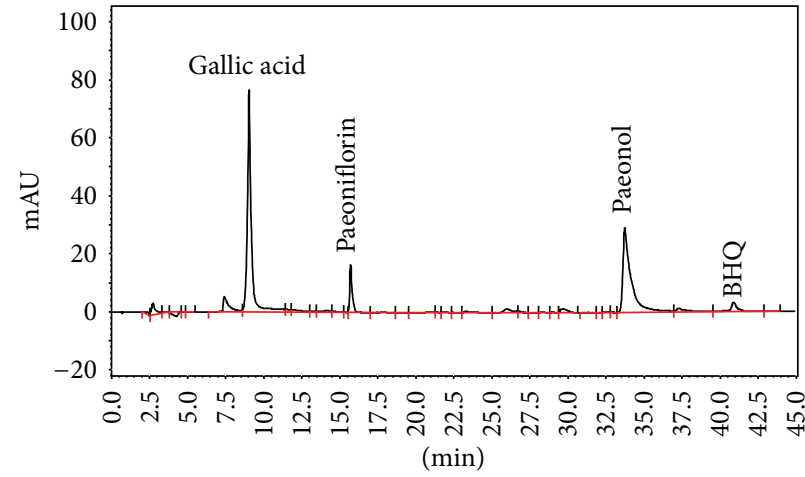

(a)

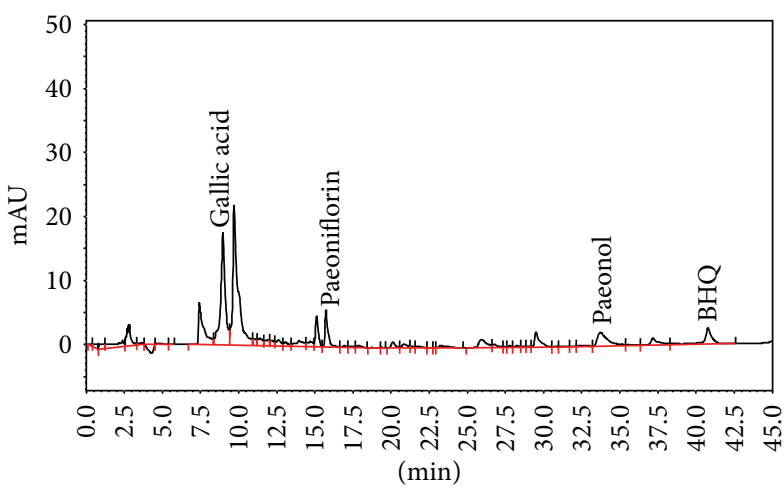

(b)

Figure 1: HPLC chromatograms of Paeonia lactiflora at $250 \mathrm{~nm}$. Trace (a) Standard, gallic acid $(50 \mu \mathrm{g} / \mathrm{mL})$, paeoniflorin $(100 \mu \mathrm{g} / \mathrm{mL})$, and paeonol $(50 \mu \mathrm{g} / \mathrm{mL})$. (b) PLex $(2.5 \mathrm{mg} / \mathrm{mL})$ The content of paeoniflorin in PLex is $9.94 \mu \mathrm{g} / \mathrm{mg}$. BHQ: tert-butylhydroquinone as an internal standard.

(EEL) were determined by computerized planimetry. The luminal area, intimal area, medial area, and intimal/medial ratios were calculated. The intimal area was calculated by subtracting the luminal from the IEL area, and medial area was determined by subtracting the IEL area from the EEL area [19]. The ratio of intimal to medial area (I/M ratio) was calculated and analyzed. Proliferating cell nuclear antigen (PCNA) was also determined in arterial sections [20].

2.7. Cell Proliferation Assay. A7r5 proliferation was measured by determining cell number. The cells $\left(1 \times 10^{4}\right.$ cells/well $)$ were seeded onto 12 well plates and grown in DMEM containing $10 \%$ FBS for $24 \mathrm{hr}$. The cells were then cultured with medium containing PDGF (30 ngmL) and PLex (50, 100, and $200 \mu \mathrm{g} / \mathrm{mL})$ or PF $(5,10$, and $20 \mu \mathrm{M})$ for 24 to $72 \mathrm{hr}$. MTT $(200 \mu \mathrm{L}, 0.5 \mathrm{mg} / \mathrm{mL})$ was added to each well and incubated for $4 \mathrm{hr}$. Five hundred $\mu \mathrm{L}$ of DMSO was added to each well to solubilize the formed formazan crystals. The optical density was measured at $570 \mathrm{~nm}$ with a spectrophotometer (BioRad Laboratories, Hercules, CA, USA).

2.8. In Vitro Wound Healing Assay. To evaluate the impact of PLex $(50,100$, and $200 \mu \mathrm{g} / \mathrm{mL})$ and PF $(5,10$, and $20 \mu \mathrm{M})$ on VSMC migration, a wound healing assay was used. A7r5 cells $\left(2 \times 10^{5}\right.$ cells/well $)$ were plated in 6 -well plates, and the wound was induced with a single scratch using a sterile pipette tip. Cells were then incubated with or without PDGF (30 ng/mL), PLex $(50,100$, and $200 \mu \mathrm{g} / \mathrm{mL})$ and PF $(5,10$, and $20 \mu \mathrm{M}$ ) in serum-reduced DMEM (containing $0.5 \%$ fetal bovine serum). The rate of wound closure was determined by photographing cells using a phase-contrast microscope at 24, 48 , and $72 \mathrm{hr}$. Cell migration was expressed as the migration distance of drug-treated cells ( $\mathrm{mm}$ ) divided by the migration distance of untreated cells ( $\mathrm{mm})$.

2.9. Transwell Migration Study. The effects of PLex and PF on VSMC migration were further investigated using a transwell migration chamber with a collagen-coated polycarbonate filter. A7r5 cells $\left(5 \times 10^{5}\right.$ cells/well $)$ were incubated on the transwell apparatus (a 6.5- $\mathrm{mm}$ polyethylene terephthalate membrane with $8-\mu \mathrm{m}$ pores; Millicell, Millipore Inc, Billerica, MA01821, USA) and treated with PDGF (30 ng) and PLex $(50,100$, and $200 \mu \mathrm{g} / \mathrm{mL})$ or $\mathrm{PF}(5,10$, and $20 \mu \mathrm{M})$ for $48 \mathrm{hr}$. The cells were then trypsinized, resuspended in $0.5 \%$ FBS medium. FBS/DMEM (10\%) was added to the bottom chamber of each well as the chemoattractant. Cells were allowed to migrate through the membrane to the underside of the apparatus for $8 \mathrm{hr}$ and were then fixed with methanol for $10 \mathrm{~min}$ and stained with Giemsa solution for $30 \mathrm{~min}$. The cells migrating to the lower outside of the insert membrane were counted manually under a microscope using the NISElements software (Nikon Inc, Melville, NY, USA).

2.10. Protein Preparation and Western Blot Analysis. A7r5 cells $\left(5 \times 10^{6}\right.$ cells $)$ were seeded in $10 \mathrm{~cm}$ dish and treated with $\mathrm{PF}(5,10$, and $20 \mu \mathrm{M})$ for $4 \mathrm{hr}$ for phosphor-protein expression and for $48 \mathrm{hr}$ for protein expression. The cells were harvested and washed with cold $1 \mathrm{X}$ PBS. The total protein concentration was determined using a BCA assay kit (Pierce Biotechnology Inc., Rockford, IL, USA). Equal amounts of cell lysate were run on $10 \%-12 \%$ SDS-polyacrylamide gel electrophoresis (SDS-PAGE) and electrotransferred to polyvinylidene fluoride membranes (PVDF, Thermo Scientific Inc, Waltham, PA, USA) using iBotTM Dry Blotting System (Invitrogen). The blot was soaked in blocking buffer (5\% nonfat dry milk/0.05\% Tween 20 in 20 mM TBS at pH 7.6) at room temperature for $1 \mathrm{hr}$ and then incubated with antiMMP-2, anti-MMP-9, anti-Ras, anti-ERK, anti-phosphoERK1/2, anti-MEK, and anti-phosphor-MEK1/2 and $\beta$-actin antibodies in blocking buffer, respectively, at $4^{\circ} \mathrm{C}$ overnight. $\beta$-Actin was used as an internal loading control. Membranes were washed with Tris-buffered saline/Tween 20 three times for $10 \mathrm{~min}$ and then incubated with secondary horseradish peroxidase (HRP-) conjugated antibody. The blots were developed using a chemiluminescence (ECL) detection kit (Millipore, Billerica, MA, USA) followed by development on Kodak BioMax MR film (Eastman Kodak, Rochester, NY, USA). All results are from 6 independent experiments. 


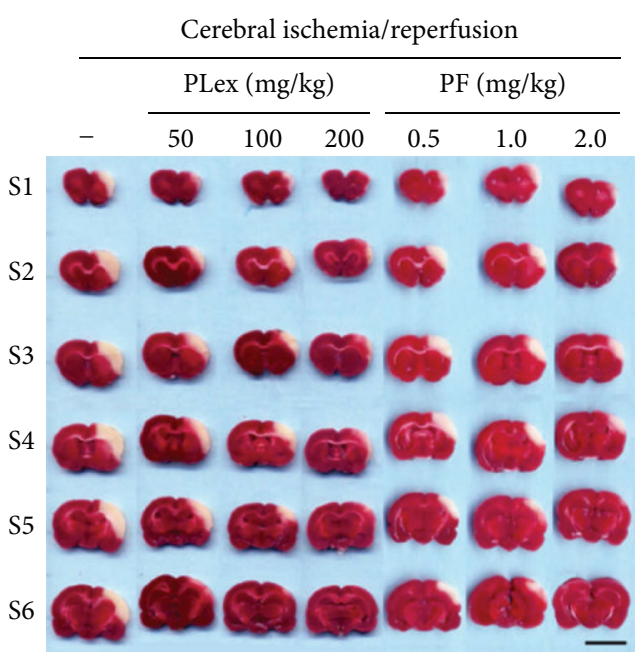

(a)

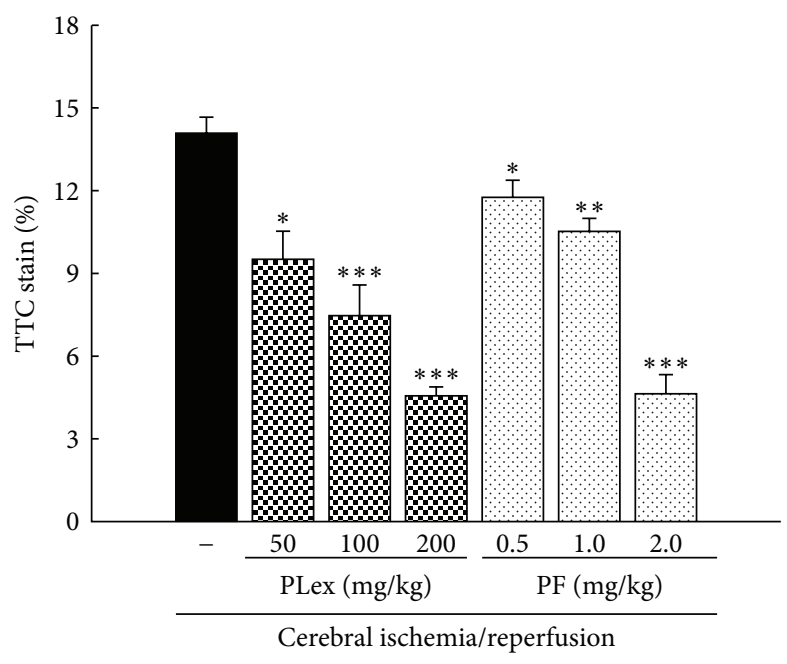

(b)

Figure 2: Effects of PLex and PF on cerebral infarction induced by ischemia/reperfusion injury. Coronal section of brain after ischemia for $90 \mathrm{~min}$ and followed by reperfusion for $24 \mathrm{~h}$. Then staining with TTC, the infarction areas appeared white and noninfarction areas appeared red-purple in color. S1 $\rightarrow$ S6: slices from frontal lobe. (a) Treatment with PLex and PF. (b) Statistic percentage of cerebral infarction area of PLex and PF. Scale bar $=1 \mathrm{~cm} .{ }^{*} P<0.05,{ }^{* *} P<0.01$, and ${ }^{* *} P<0.001$ compared with the control group $(n=6)$.

2.11. Statistical Analysis. The data are represented as mean \pm SE. Groups were compared by one-way analysis of variance (ANOVA) followed by Scheffe's test. A $P$ value $<0.05$ was considered statistically significant.

\section{Results}

3.1. Effects of PLex and PF on Cerebral Infarct Volume. Blood flow was blocked for $90 \mathrm{~min}$ in both common carotid arteries and the right cerebral artery and then reperfused for $24 \mathrm{hr}$. After staining with TTC, the infarction areas were visibly white, and noninfarction areas were red-purple in color. PLex and PF significantly decreased the infarct volume in a dose-dependent manner (Figure 2(a)). PLex (50, 100, and $200 \mathrm{mg} / \mathrm{kg}$ ) reduced the infarct area by $32.49 \%, 47.00 \%$, and $67.63 \%$. The inhibitory percentages of PF $(0.5,1.0$, and $2.0 \mathrm{mg} / \mathrm{kg}$ ) on the infarct area were $16.51 \%, 25.27 \%$, and $67.08 \%$ as shown in Figure 2(b), respectively.

3.2. Effect of PLex on Intimal Hyperplasia. After carotid ligation, mice were treated with PLex (100 and $200 \mathrm{mg} / \mathrm{kg}$ ) or distilled water (control group) for 4 weeks. The carotid artery, absolute lumen area, intimal area, medial area, and intima/media (I/M) ratios were determined. The morphology of the intima/medial area was abnormal after carotid ligation for 4 weeks $(\mathrm{I} / \mathrm{M}$ ratio $=2.29 \pm 0.15)$. The PLex-treated mice significantly improved intimal hyperplasia after carotid ligation compared with the control group. I/M ratio was 1.69 $\pm 0.11(100 \mathrm{mg} / \mathrm{kg})$ and $1.50 \pm 0.08(200 \mathrm{mg} / \mathrm{kg})$ (Figures 3(a) and $3(\mathrm{~b})$ ). The average inhibitory rate of PLex was $26.14 \%$ $(100 \mathrm{mg} / \mathrm{kg})$ and $34.67 \%(200 \mathrm{mg} / \mathrm{kg})$ compared with the control group (Figure 3(e)). Arterial sections stained to detect the proliferating cell nuclear antigen (PCNA) are shown in Figures 3(c) and 3(d). The percentages of PCNA positive cells per total cells were $40.44 \pm 1.75 \%$ in the control group, and $26.92 \% \pm 2.40 \%$ and $19.79 \% \pm 2.69 \%$ in PLex $(100$ and $200 \mathrm{mg} / \mathrm{kg}$ ) treated groups, respectively. The average inhibitory rate of PLex on PCNA was $33.43 \%(100 \mathrm{mg} / \mathrm{kg})$ and $51.06 \%(200 \mathrm{mg} / \mathrm{kg})$ compared with the control group (Figure 3(f)).

3.3. Effects of PLex and PF on VSMC Proliferation. To investigate the effects of PLex and PF on PDGF-stimulated VSMC proliferation, the cells were exposed to $50-200 \mu \mathrm{g} / \mathrm{mL}$ of PLex or 5-20 $\mu \mathrm{M}$ PF for $24-72 \mathrm{hr}$. Figure 4(a) shows that 50-200 $\mu \mathrm{g} / \mathrm{mL}$ PLex inhibited PDGF-stimulated VSMC proliferation. The inhibitory percentages of PLex $(200 \mu \mathrm{g} / \mathrm{mL})$ were $18 \%, 3.05 \%$ and $13.08 \%$ at 24,48 , and $72 \mathrm{hr}$, respectively. Figure 4(b) showed that the inhibitory percentages of PF (5 $20 \mu \mathrm{M}$ ) were $18.98 \%, 22.45 \%$, and $20.75 \%$ at 24,48 , and $72 \mathrm{hr}$, respectively.

3.4. Effect of PLex and PF on VSMC Migration. The effects of PLex and PF on VSMC migration were evaluated by woundhealing at 24,48 , and $72 \mathrm{hr}$ after treatment. VSMCs were pretreated with or without PLex $(50,100$, and $200 \mu \mathrm{g} / \mathrm{mL})$ and $\mathrm{PF}(5 \mu \mathrm{M}, 10 \mu \mathrm{M}$, and $20 \mu \mathrm{M})$, then stimulated with PDGF (30 ng/mL) (Figures 5(a) and 6(a)). The migrated cell numbers induced by PDGF across the membrane were significantly inhibited by both PLex (Figure 5(b)) and PF (Figure 6(b)). The effects of PLex and PF on VSMC migration were further confirmed by a modified Boyden chamber experiment. VSMC numbers were reduced by pretreatment with PLex (Figure 7(a)) and PF (Figure 7(b)). The inhibitory percentages were $13.16 \%, 34.01 \%$, and $37.87 \%$ by PLex (50, 100 , and $200 \mu \mathrm{g} / \mathrm{mL}$ ) (Figure 7 (c)) and $36.74 \%$ and $54.42 \%$ by $\mathrm{PF}(10$ and $20 \mu \mathrm{M}$ ) (Figure $7(\mathrm{~d})$ ) compared with a positive control group treated with PDGF, respectively. 

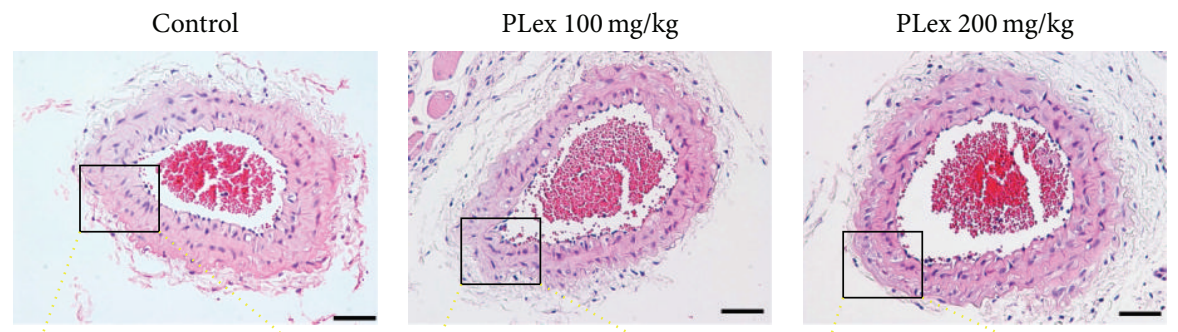

(a)
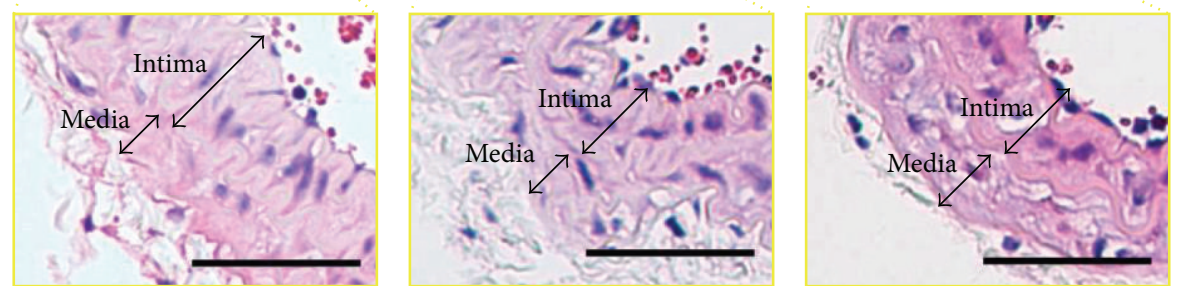

(b)
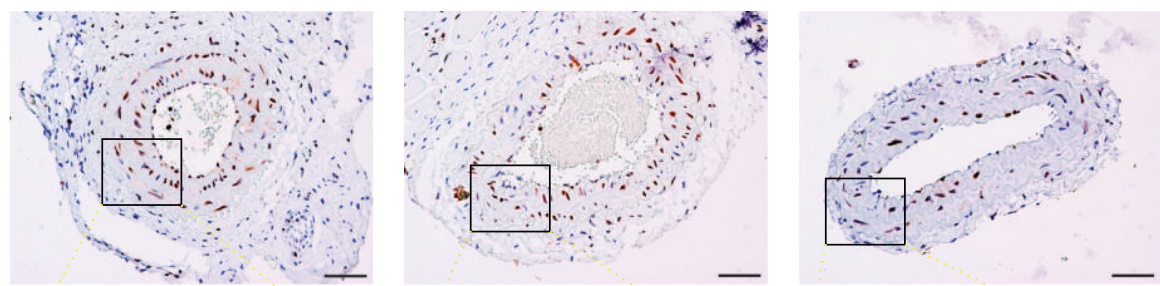

(c)
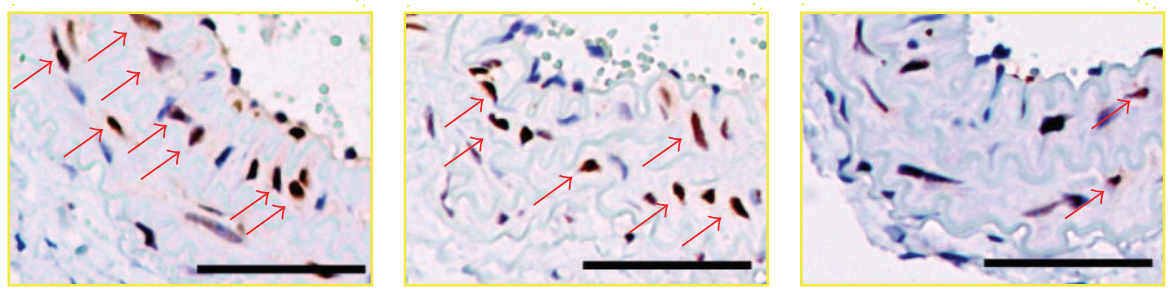

(d)
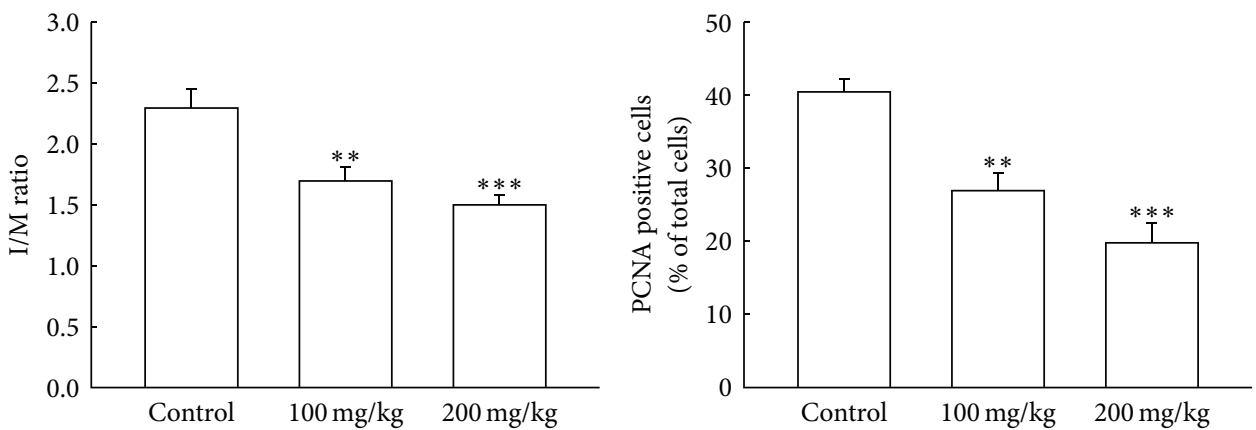

(e)

(f)

Figure 3: Effects of PLex on carotid-ligation induced intimal hyperplasia in mice. Different doses of PLex (100 and $200 \mathrm{mg} / \mathrm{kg}$ ) were orally administered once a day for 28 days and the sham group received normal distilled water. (a) and (b) represent photomicrographs of hematoxylin-eosin staining of arterial sections 28 days after carotid ligation, and (c) and (d) represent PCNA-immunoreactivity staining of arterial sections (200x). (e) Severity of intimal hyperplasia was calculated according to intima/media area (I/M) ratio. (f) Percentage of PCNA positive cells per total cells. The arrow was indicating the PCNA-positive cell. Scale bar $=50 \mu \mathrm{m} .{ }^{* *} P<0.01$ and ${ }^{* * *} P<0.001$ compared with the control group $(n=5)$. 

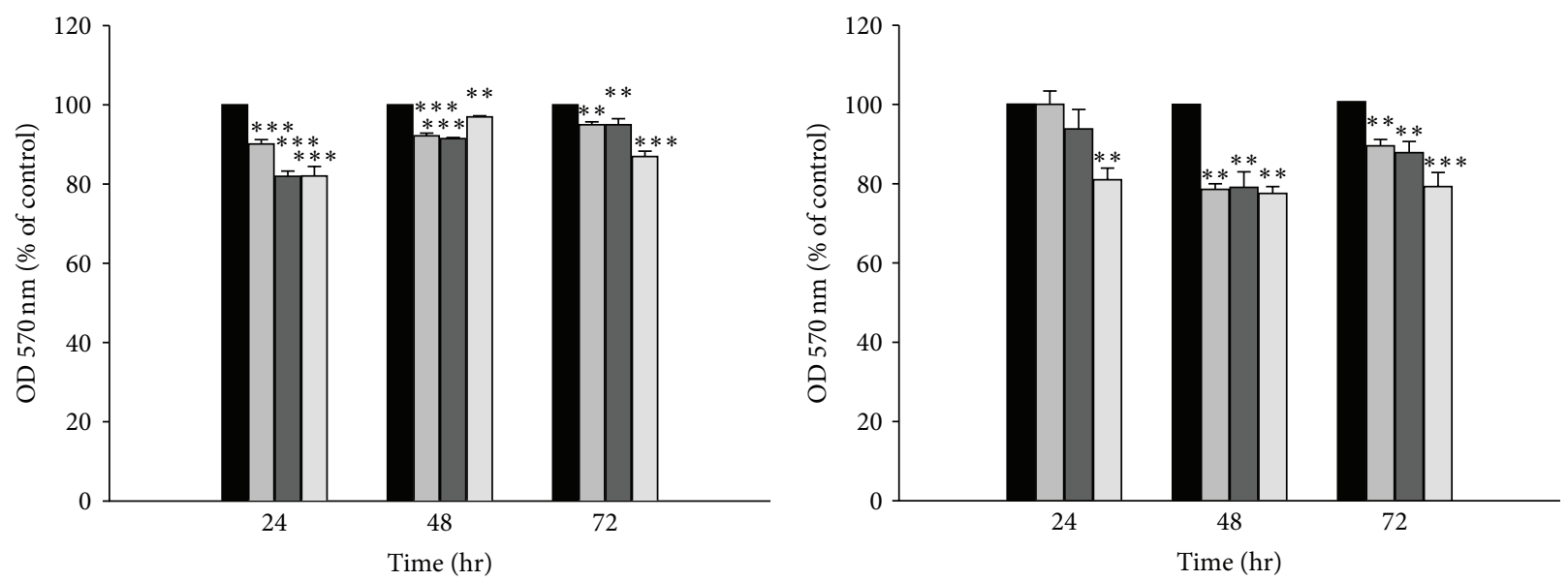

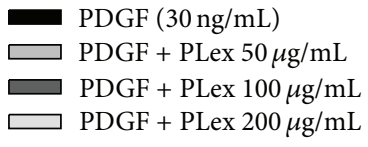

(a)

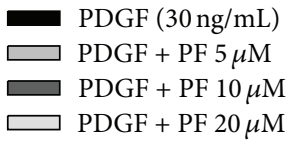

(b)

Figure 4: Effects of PLex and PF on PDGF-induced VSMC proliferation by MTT assay. PLex (a) and PF (b) inhibit vascular smooth cell proliferation in response to PDGF in a dose-dependent and a time-dependent manner. Statistical difference in 24,48 , and $72 \mathrm{hr}$ at different concentrations of PLex (a) and PF (b). ${ }^{* *} P<0.01,{ }^{* * *} P<0.001$ compared with PDGF control group $(n=10)$.

3.5. Effects of PF on MMPs and Ras/MEK/ERK Protein Levels. Protein levels of VSMC were examined by western blotting. Various concentrations of PF significantly reduced protein abundance of Ras, MEK, p-MEK, and p-ERK (Figure 8). PF reduced the expressions of MMP-2 and MMP-9. However, there is no statistical significance. Percentages reduction of PF $(5,10$, and $15 \mu \mathrm{M})$ on protein levels were as follows: Ras were $16.5 \%, 24.25 \%$, and $32.75 \%$, respectively; MEK were $16.8 \%$, $18.6 \%$, and $18.6 \%$, respectively; p-MEK were $4.67 \%, 23.33 \%$, and $42.00 \%$, respectively; p-ERK were $4.67 \%, 13.67 \%$, and $39.33 \%$, respectively.

\section{Discussion}

Cerebral ischemia induces hypoxia which can cause brain tissue damage and reperfusion-induced reoxygenation often exacerbates tissue injury and inflammation [21]. Inflammation is a major contributor to stroke-related brain injury. Individual components of the inflammatory cascade may have detrimental or beneficial effects depending on the stage of tissue injury, the magnitude of the response, and whether these components stimulate neuroprotective pathways [2224].

Traditional Chinese herbal medicine has a long history as a treatment for conditions associated with stroke and recent reports support such an approach [25]. We found that administration of PLex and PF significantly reduced cerebral infarction size, which may be acting through PF. PF has a characteristic monoterpene glucoside which has an anti-inflammatory effect on the cerebral infarction $[17,26]$. There have been no reports on the anticerebral ischemic effect of Paeonia lactiflora. Only the protective effects of Guizhi-Fuling-Capsules
(GZFLC) on rat brain ischemia/reperfusion injury were reported [27]. It is suggested that the protective effect of GZFLC on rat brain ischemia-reperfusion injury is partly due to its inhibition of proinflammatory cytokines IL-1 $\beta$ and TNF $\alpha$ and upregulated expressions of anti-inflammatory cytokines IL-10 [27]. Paeonia lactiflora is one of the component herbal of GZFLC. PF, a component in PLex, inhibits $\mathrm{NF} \kappa \mathrm{B}$ expression in chronic hypoperfusion rat and has anti-inflammatory properties. PF reduces cerebral infarction area by inhibiting $\mathrm{NF} \kappa \mathrm{B}, \mathrm{IL}-1 \beta$, and $\mathrm{TNF} \alpha$ [17]. Data from this study revealed that PLex inhibited intimal hyperplasia via the action of PF on Ras/MEK/ERK signaling pathway modulation.

Blood vessels in response to injury or atherosclerosis can develop intimal thickening, vessel occlusion, and cerebral infarction $[14,28,29]$. PDGF, which is produced by VSMC, vascular endothelial cells, platelets, or macrophages, stimulates VSMC proliferation and migration. PDGF acts via mitogen-activated protein kinase and it plays a pivotal role in intimal hyperplasia in the injured vascular walls [14, 28, 29]. PDGF receptors were markedly upregulated after injury to the vessel wall [30], and an antibody to PDGF inhibited the neointimal smooth muscle accumulation after angioplasty [31]. PDGF activates the tyrosine kinase receptor and triggers a cascade of tyrosine phosphorylations that lead to the formation of a ternary complex connecting the receptor to ras. Ras proteins are active transducers of mitogenic signals from the plasma membrane to the nucleus in many cell types. Active ras binds the serine protein kinase raf, which activates MEK/ERK signaling cascade to regulate gene expression. It has been reported that modulation of VSMC growth has critical therapeutic implications [32]. MEK (MAPK; 


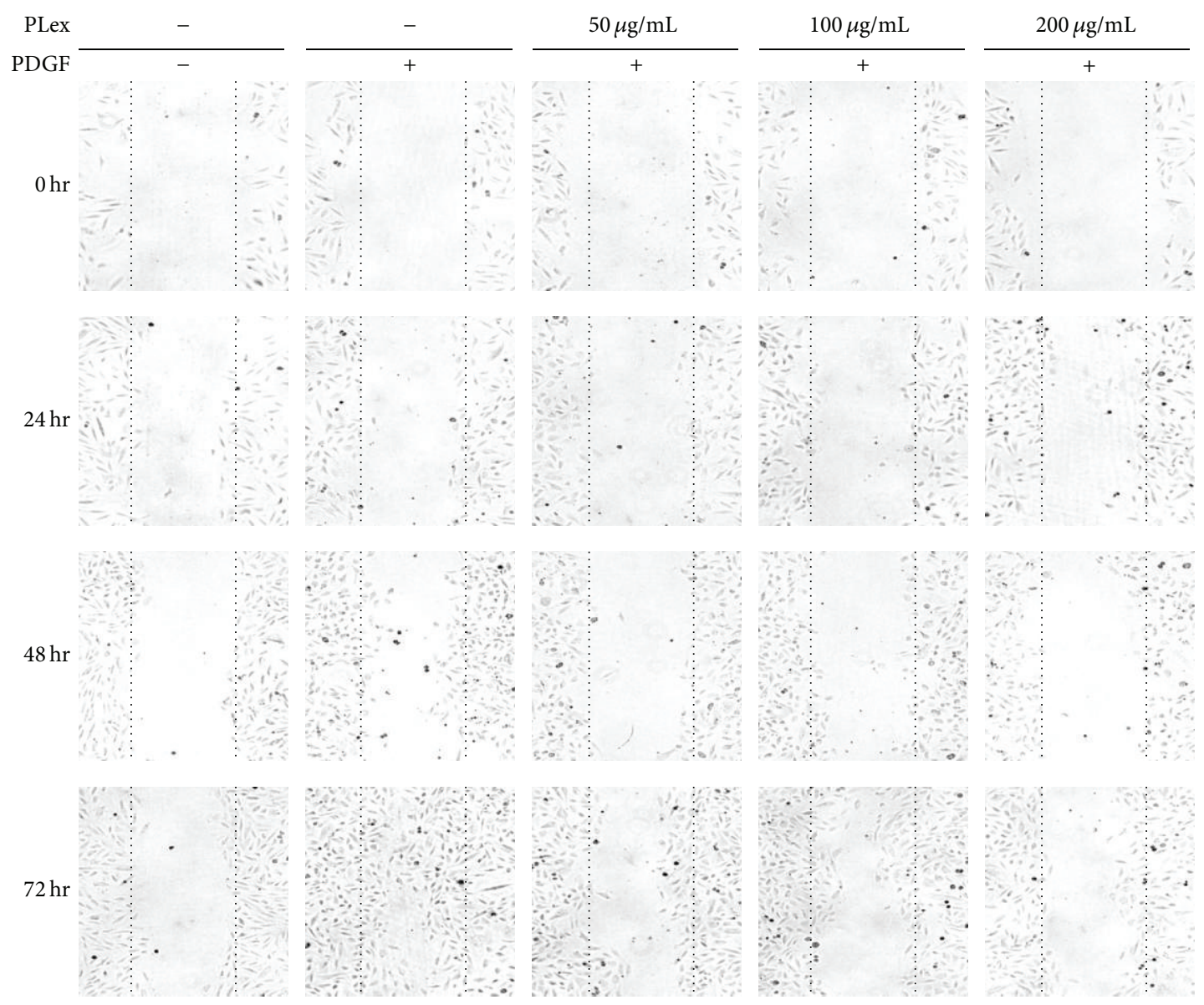

(a)

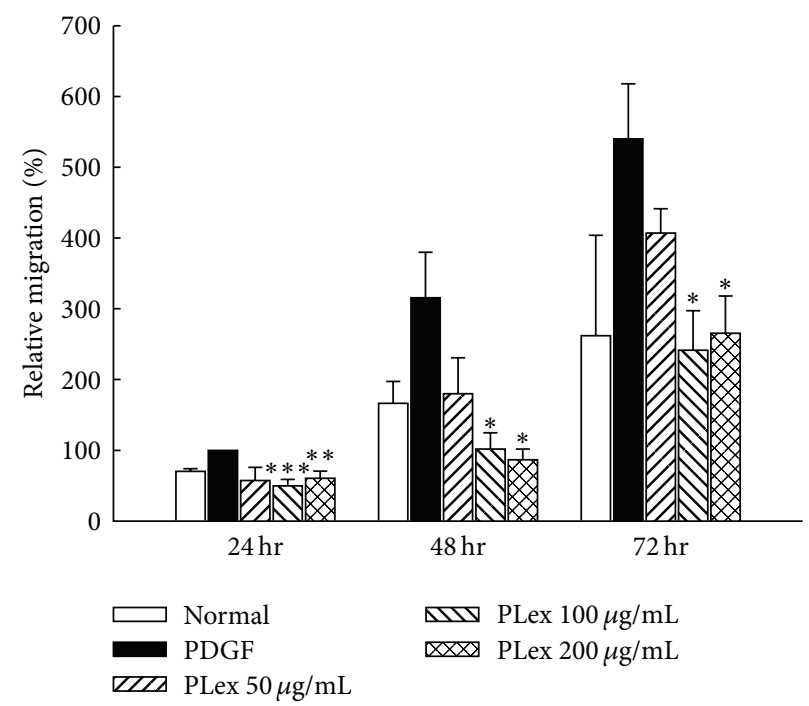

(b)

FIgURe 5: Effects of PLex on PDGF-induced VSMC migration by wound healing assay. (a) A typical trace of PLex (5, 10, and 20 $\mu \mathrm{g} / \mathrm{mL})$ inhibited in response to PDGF-induced VSMC migration. (b) Statistical differences in 24, 48, and $72 \mathrm{hr}$ at different PLex concentrations, respectively. Normal group was treated with vehicle solution. ${ }^{*} P<0.05,{ }^{* *} P<0.01$, and ${ }^{* * *} P<0.001$ compared with PDGF control group $(n=6)$. 


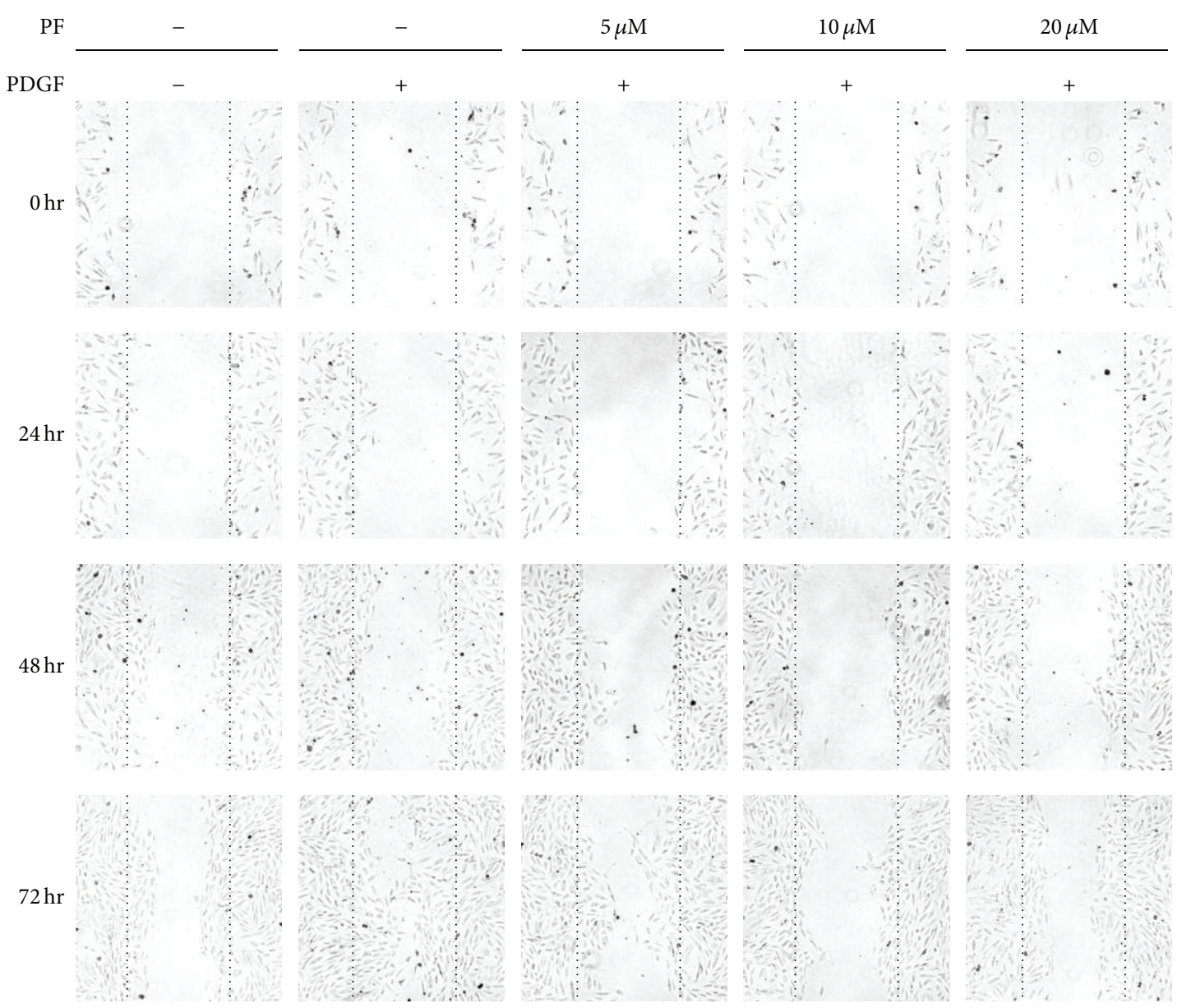

(a)

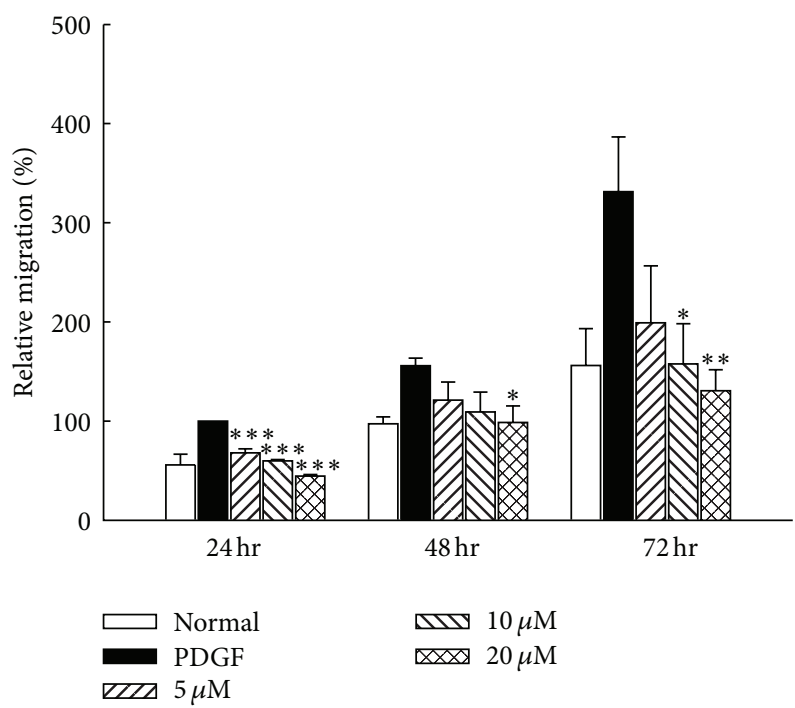

(b)

FIGURE 6: Effects of PF on PDGF-induced VSMC migration by wound healing assay. (a) A typical trace of PF $(5,10$, and $15 \mu \mathrm{M})$ inhibited in response to PDGF-induced VSMC migration. (b) Statistical differences in 24,48 , and $72 \mathrm{hr}$ at different PF concentrations, respectively. Normal group was treated with vehicle solution. ${ }^{*} P<0.05,{ }^{* *} P<0.01$, and ${ }^{* * *} P<0.001$ compared with PDGF control group $(n=6)$. 


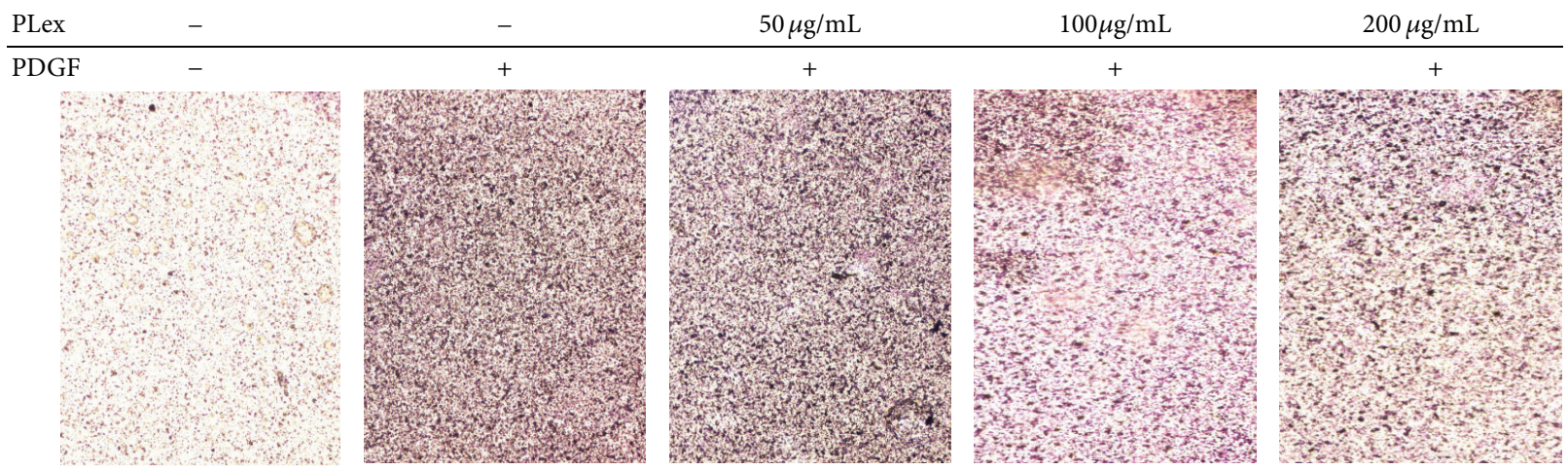

(a)

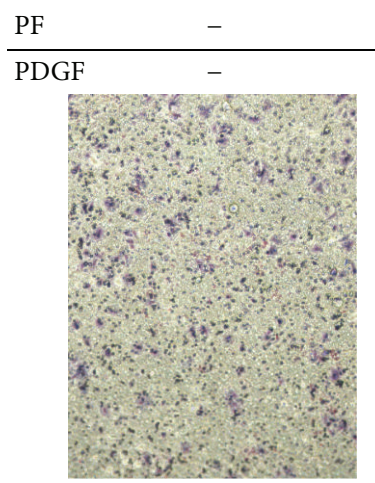

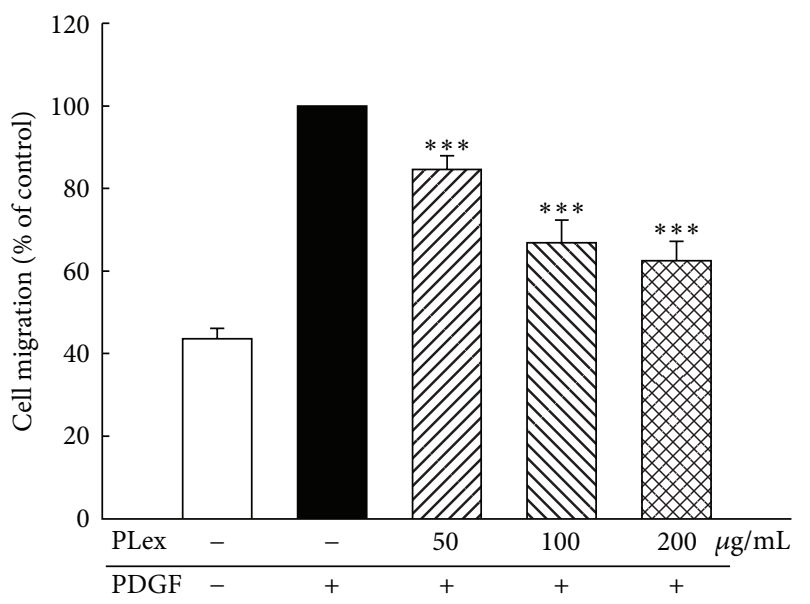

(c)
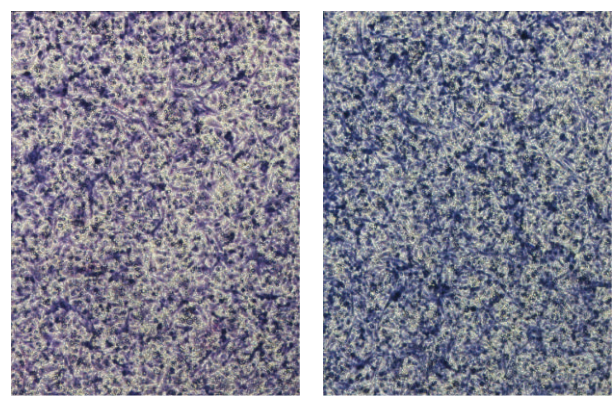

(b)

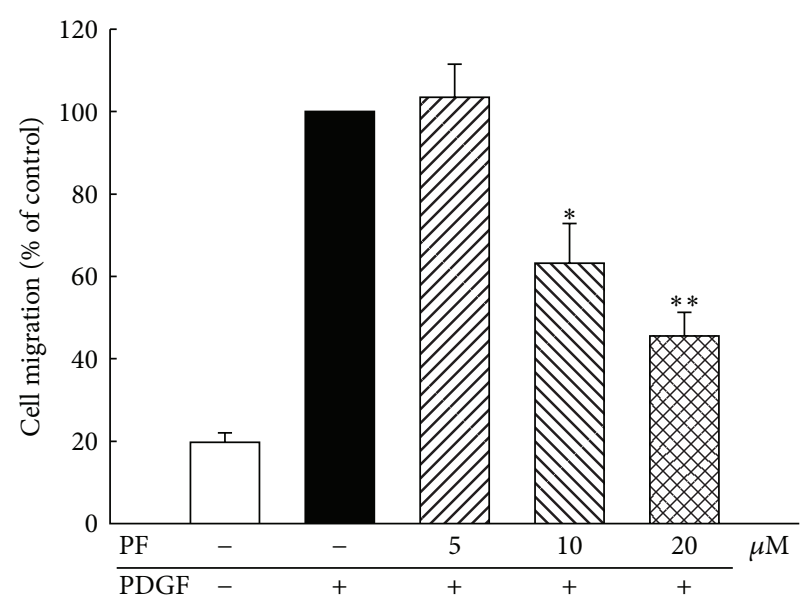

(d)

FIGURE 7: Effects of PLex and PF on PDGF-induced VSMC migration by transwell assay. PLex (a) and PF (b) inhibit vascular smooth cells migration in response to PDGF in a dose-dependent and a time-dependent manner. Statistical differences of PLex (c) and PF (d) inhibit vascular smooth cells migration in response to PDGF, ${ }^{* * *} P<0.001$ compared with PDGF treated group $(n=6)$.

mitogen-activated protein kinase) pathways play an important role in promoting VSMC proliferation [33] and are activated by vascular injury. The MAPK/ERK pathway is a series of protein reactions in cells which are phosphorylated during PDGF-stimulated cell migration [34]. This cascade culminates in the activation of nuclear transcription factors [35]. Most peptidic growth factors (GFs) that act as mitogens for different cell types bind to tyrosine kinase receptors and trigger complex intracellular signal transduction pathways leading to cell proliferation. Among the early events induced by GFs, cytosolic calcium increase plays a key role [36]. Elevation of intracellular calcium by ionomycin has been reported to increase migration of vascular smooth muscle cells [37]. Previous reports indicated that PF antagonizes veratrine-induced isolated rat aorta contraction which may be mediated by blocking intracellular calcium [38]. Paeoniae rubra relaxes vascular smooth muscle via inhibition of $\mathrm{L}$ type $\mathrm{Ca}^{2+}$ channels [39]. In the present study, PF attenuated 

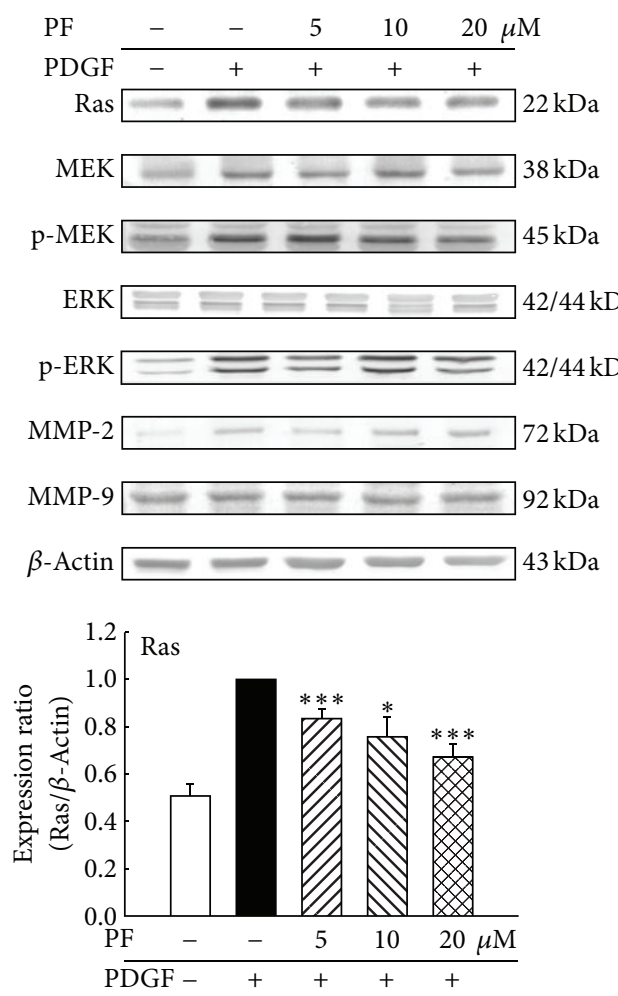
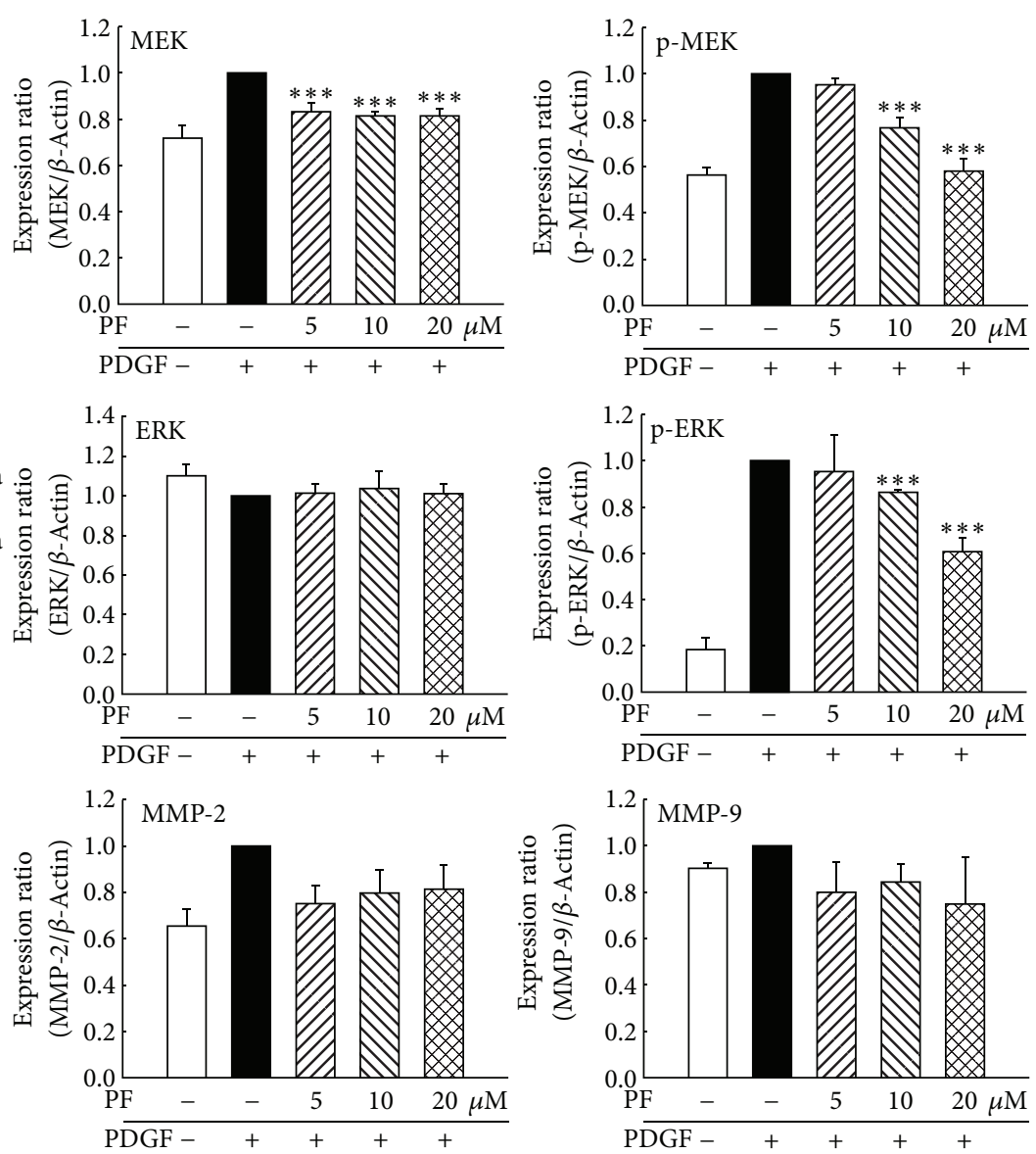

FIGURE 8: Effects of PF on Ras/MEK/ERK protein expression in PDGF-induced VSMCs. The protein expressions were determined by western blot analysis. Ras, MEK, p-MEK, and p-ERK were markedly inhibited in a dose-dependent manner. ${ }^{*} P<0.05$ and ${ }^{* * *} P<0.001$ compared with PDGF control group $(n=6)$.

the PDGF-stimulated Ras expression in a dose-dependent manner possibly by inhibiting $\mathrm{Ca}^{2+}$ channels.

When activated MAPK ( $\mathrm{p}$-ERK) translocates into the nucleus, multiple cytoplasmic matrix and transcription factors (matrix metalloproteinases; MMPs) are phosphorylated. MMPs regulate migration, proliferation, and death of vascular smooth muscle cells by degrading matrix and nonmatrix substrates [40]. MMP plays a vital role in the degradation of the extracellular matrix that facilitates VSMC migration. During the process of atherosclerosis and neointimal formation, various cytokines and growth factors stimulate VSMC to express MMP [7]. MMP-2 and MMP-9 are necessary for the migration of many cell types [41]. Inhibition of the activated ERK pathway by drugs or gene therapy can reduce neointimal hyperplasia [42]. Inhibition of PDGF-stimulated VSMC proliferation and migration can attenuate the development of intimal hyperplasia, which may have therapeutic potential in the prevention or treatment of cerebrovascular diseases [32].

In conclusion, results of the present study indicate that Paeonia lactiflora ameliorates cerebral ischemia and arterial intimal hyperplasia which is mediated by paeoniflorin via modulation of Ras/MEK/ERK pathway of vascular smooth muscle cells.

\section{Conflict of Interests}

The authors declared that there is no conflict of interests.

\section{Acknowledgments}

The authors would like to thank the National Sciences Council (Taipei, Taiwan) and China Medical University (Taichung, Taiwan) for supporting this work (NSC96-2320- B-039-014MY2, NSC101-2320-B-039-026, CMU96-201, CMU99-COL42-1, and CMU99-COL-42-2).

\section{References}

[1] A. N. Hasso, W. A. Stringer, and K. D. Brown, "Cerebral ischemia and infarction," Neuroimaging Clinics of North America, vol. 4, no. 4, pp. 733-752, 1994.

[2] H. K. Eltzschig and C. D. Collard, "Vascular ischaemia and reperfusion injury," British Medical Bulletin, vol. 70, pp. 71-86, 2004.

[3] H. C. Lowe, S. N. Oesterle, and L. M. Khachigian, "Coronary in-stent restenosis: current status and future strategies," Journal of the American College of Cardiology, vol. 39, no. 2, pp. 183-193, 2002. 
[4] P. W. Serruys, P. De Jaegere, F. Kiemeneij et al., "A comparison of balloon-expandable-stent implantation with balloon angioplasty in patients with coronary artery disease," The New England Journal of Medicine, vol. 331, no. 8, pp. 489-495, 1994.

[5] R. Ross, "The pathogenesis of atherosclerosis: a perspective for the 1990s," Nature, vol. 362, no. 6423, pp. 801-809, 1993.

[6] T. R. Kohler and A. Jawien, "Flow affects development of intimal hyperplasia after arterial injury in rats," Arteriosclerosis and Thrombosis, vol. 12, no. 8, pp. 963-971, 1992.

[7] Y. H. Li, H. C. Chung, S. L. Liu, T. H. Chao, and J. C. Chen, "A novel inhibitory effect of Antrodia camphorata extract on vascular smooth muscle cell migration and neointima formation in mice," International Heart Journal, vol. 50, no. 2, pp. 207-220, 2009.

[8] T. Asahara, C. Bauters, C. Pastore et al., "Local delivery of vascular endothelial growth factor accelerates reendothelialization and attenuates intimal hyperplasia in balloon-injured rat carotid artery," Circulation, vol. 91, no. 11, pp. 2793-2801, 1995.

[9] Y. Sakata, F. Xiang, Z. P. Chen et al., "Transcription factor $\mathrm{CHF} 1 / \mathrm{Hey} 2$ mediates neointimal formation by regulation of growth factor responsiveness and Racl activation," Arteriosclerosis Thrombosis and Vascular Biology, vol. 24, no. 5, pp. E34E34, 2004.

[10] K. Uchida, M. Sasahara, N. Morigami, F. Hazama, and M. Kinoshita, "Expression of platelet-derived growth factor Bchain in neointimal smooth muscle cells of balloon injured rabbit femoral arteries," Atherosclerosis, vol. 124, no. 1, pp. 9-23, 1996.

[11] M. Kaiser, C. M. Weyand, J. Bjornsson, and J. J. Goronzy, "Platelet-derived growth factor, intimal hyperplasia, and ischemic complications in giant cell arteritis," Arthritis and Rheumatism, vol. 41, no. 4, pp. 623-633, 1998.

[12] Ming Wei Liu, G. S. Roubin, and S. B. King, "Restenosis after coronary angioplasty: potential biologic determinants and role of intimal hyperplasia," Circulation, vol. 79, no. 6, pp. 1374-1387, 1989.

[13] K. E. Bornfeldt, E. W. Raines, T. Nakano, L. M. Graves, E. G. Krebs, and R. Ross, "Insulin-like growth factor-I and platelet-derived growth factor-BB induce directed migration of human arterial smooth muscle cells via signaling pathways that are distinct from those of proliferation," Journal of Clinical Investigation, vol. 93, no. 3, pp. 1266-1274, 1994.

[14] B. Chandrasekar and J. F. Tanguay, "Platelets and restenosis," Journal of the American College of Cardiology, vol. 35, no. 3, pp. 555-562, 2000.

[15] H. Ishida, M. Takamatsu, K. Tsuji, and T. Kosuge, "Studies on active substances in herbs used for Oketsu (stagnant blood) in Chinese medicine. VI. On the anticoagulative principle in Paeoniae Radix," Chemical and Pharmaceutical Bulletin, vol. 35, no. 2, pp. 849-852, 1987.

[16] Y. F. Chen, H. Y. Tsai, and H. C. Chen, "The effects of veratri formosani rhizoma on some central actions of paeoniae radix," Chinese Pharmaceutical Journal, vol. 40, no. 2, pp. 11-16, 1988.

[17] N. Y. Tang, C. H. Liu, C. T. Hsieh, and C. L. Hsieh, "The anti-inflammatory effect of paeoniflorin on cerebral infarction induced by ischemia-reperfusion injury in sprague-dawley rats," American Journal of Chinese Medicine, vol. 38, no. 1, pp. 51-64, 2010.

[18] K. J. Wu, M. T. Hsieh, C. R. Wu, W. G. Wood, and Y. F. Chen, "Green tea extract ameliorates learning and memory deficits in ischemic rats via its active component polyphenol epigallocatechin-3-gallate by modulation of oxidative stress and neuroinflammation," Evidence-Based Complementary and Alternative Medicine, vol. 2012, Article ID 163106, 11 pages, 2012.

[19] J. A. McPherson, K. G. Barringhaus, G. G. Bishop et al., "Adenosine A2A receptor stimulation reduces inflammation and neointimal growth in a murine carotid ligation model," Arteriosclerosis, Thrombosis, and Vascular Biology, vol. 21, no. 5, pp. 791-796, 2001.

[20] P. A. Hall, D. A. Levison, A. L. Woods et al., "Proliferating cell nuclear antigen (PCNA) immunolocalization in paraffin sections: An index of cell proliferation with evidence of deregulated expression in some neoplasms," Journal of Pathology, vol. 162, no. 4, pp. 285-294, 1990.

[21] D. M. Yellon and D. J. Hausenloy, "Myocardial reperfusion injury-reply," The New England Journal of Medicine, vol. 357, no. 23, pp. 2409-2410, 2007.

[22] K. P. Doyle, R. P. Simon, and M. P. Stenzel-Poore, "Mechanisms of ischemic brain damage," Neuropharmacology, vol. 55, no. 3, pp. 310-318, 2008.

[23] H. Nawashiro, M. Brenner, S. Fukui, K. Shima, and J. M. Hallenbeck, "High susceptibility to cerebral ischemia in GFAPnull mice," Journal of Cerebral Blood Flow and Metabolism, vol. 20, no. 7, pp. 1040-1044, 2000.

[24] Z. G. Zhang, L. Zhang, Q. Jiang et al., "VEGF enhances angiogenesis and promotes blood-brain barrier leakage in the ischemic brain," Journal of Clinical Investigation, vol. 106, no. 7, pp. 829-838, 2000.

[25] Y. F. Chen, "Traditional Chinese herbal medicine and cerebral ischemia," Frontiers in Bioscience, vol. 4, pp. 809-817, 2012.

[26] C. L. Hsieh, C. Y. Cheng, T. H. Tsai et al., "Paeonol reduced cerebral infarction involving the superoxide anion and microglia activation in ischemia-reperfusion injured rats," Journal of Ethnopharmacology, vol. 106, no. 2, pp. 208-215, 2006.

[27] T. J. Li, Y. Qiu, J. Q. Mao, P. Y. Yang, Y. C. Rui, and W. S. Chen, "Protective effects of Guizhi-Fuling-capsules on rat brain ischemia/reperfusion injury," Journal of Pharmacological Sciences, vol. 105, no. 1, pp. 34-40, 2007.

[28] X. Yang, D. P. Thomas, X. Zhang et al., "Curcumin inhibits platelet-derived growth factor-stimulated vascular smooth muscle cell function and injury-induced neointima formation," Arteriosclerosis, Thrombosis, and Vascular Biology, vol. 26, no. 1, pp. 85-90, 2006.

[29] K. Graf, X. P. Xi, D. Yang, E. Fleck, W. A. Hsueh, and R. E. Law, "Mitogen-activated protein kinase activation is involved in platelet- derived growth factor-directed migration by vascular smooth muscle cells," Hypertension, vol. 29, no. 1, pp. 334-339, 1997.

[30] M. G. Sirois, M. Simons, and E. R. Edelman, "Antisense oligonucleotide inhibition of PDGFR- $\beta$ receptor subunit expression directs suppression of intimal thickening," Circulation, vol. 95, no. 3, pp. 669-676, 1997.

[31] G. A. A. Ferns, E. W. Raines, K. H. Sprugel, A. S. Motani, M. A. Reidy, and R. Ross, "Inhibition of neointimal smooth muscle accumulation after angioplasty by an antibody to PDGF," Science, vol. 253, no. 5024, pp. 1129-1132, 1991.

[32] A. Ross, "Atherosclerosis-an inflammatory disease," The New England Journal of Medicine, vol. 340, pp. 115-126, 1999.

[33] C. Indolfi, C. Coppola, D. Torella, O. Arcucci, and M. Chiariello, "Gene therapy for restenosis after balloon angioplasty and stenting," Cardiology in Review, vol. 7, no. 6, pp. 324-331, 1999. 
[34] I. A. Yamboliev and W. T. Gerthoffer, "Modulatory role of ERK MAPK-caldesmon pathway in PDGF-stimulated migration of cultured pulmonary artery SMCs," American Journal of Physiology, vol. 280, no. 6, pp. C1680-C1688, 2001.

[35] A. Curcio, D. Torella, and C. Indolfi, "Mechanisms of smooth muscle cell proliferation and endothelial regeneration after vascular injury and stenting," Circulation Journal, vol. 75, no. 6, pp. 1287-1296, 2011.

[36] L. Munaron, "Calcium signalling and control of cell proliferation by tyrosine kinase receptors (review)," International journal of molecular medicine, vol. 10, no. 6, pp. 671-676, 2002.

[37] R. R. Pauly, C. Bilato, S. J. Sollott et al., "Role of calcium/calmodulin-dependent protein kinase II in the regulation of vascular smooth muscle cell migration," Circulation, vol. 91, no. 4, pp. 1107-1115, 1995.

[38] H. Y. Tsai, Y. T. Lin, C. F. Chen, C. H. Tsai, and Y. F. Chen, "Effects of veratrine and paeoniflorin on the isolated rat aorta," Journal of Ethnopharmacology, vol. 66, no. 3, pp. 249-255, 1999.

[39] S. N. Jin, J. F. Wen, T. T. Wang, D. G. Kang, H. S. Lee, and K. W. Cho, "Vasodilatory effects of ethanol extract of Radix Paeoniae Rubra and its mechanism of action in the rat aorta," Journal of Ethnopharmacology, vol. 142, no. 1, pp. 188-193, 2012.

[40] A. C. Newby, "Matrix metalloproteinases regulate migration, proliferation, and death of vascular smooth muscle cells by degrading matrix and non-matrix substrates," Cardiovascular Research, vol. 69, no. 3, pp. 614-624, 2006.

[41] A. V. Chernov and A. Y. Strongin, "Epigenetic regulation of matrix metalloproteinases and their collagen substrates in cancer," Biomolecular Concepts, vol. 2, no. 3, pp. 135-147, 2011.

[42] G. Gennaro, C. Ménard, S. É. Michaud, D. Deblois, and A. Rivard, "Inhibition of vascular smooth muscle cell proliferation and neointimal formation in injured arteries by a novel, oral mitogen-activated protein kinase/extracellular signal-regulated kinase inhibitor," Circulation, vol. 110, no. 21, pp. 3367-3371, 2004. 


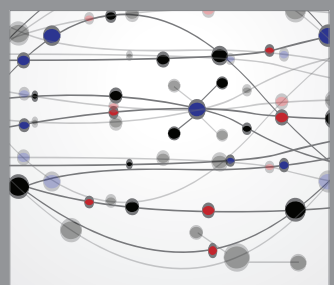

The Scientific World Journal
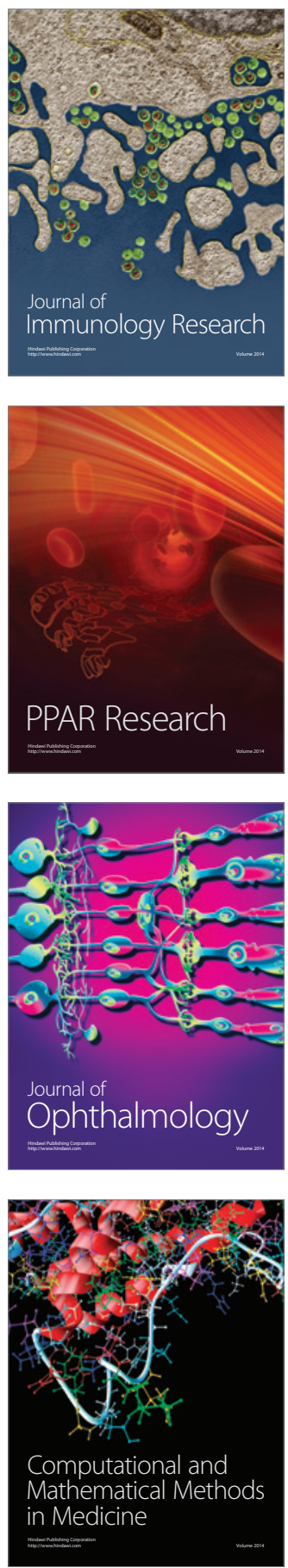

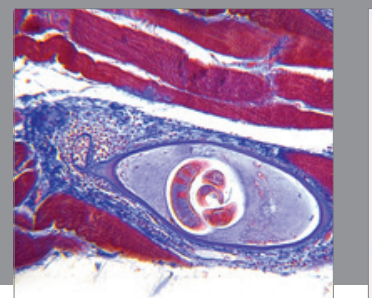

Gastroenterology

Research and Practice
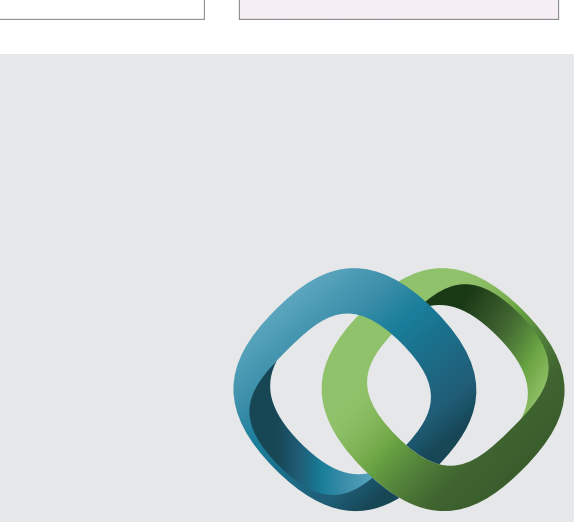

\section{Hindawi}

Submit your manuscripts at

http://www.hindawi.com
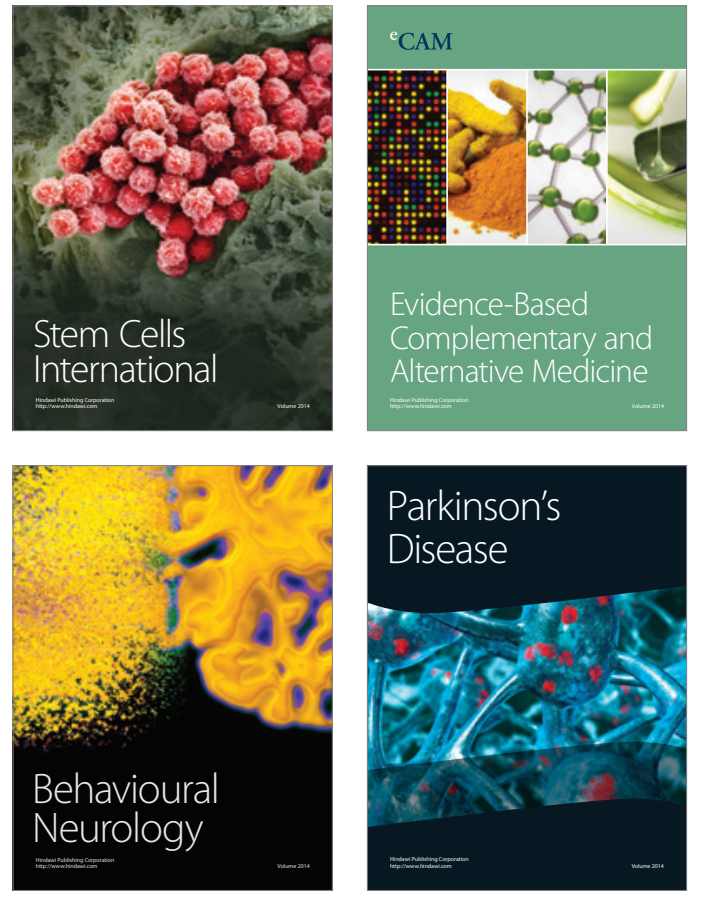
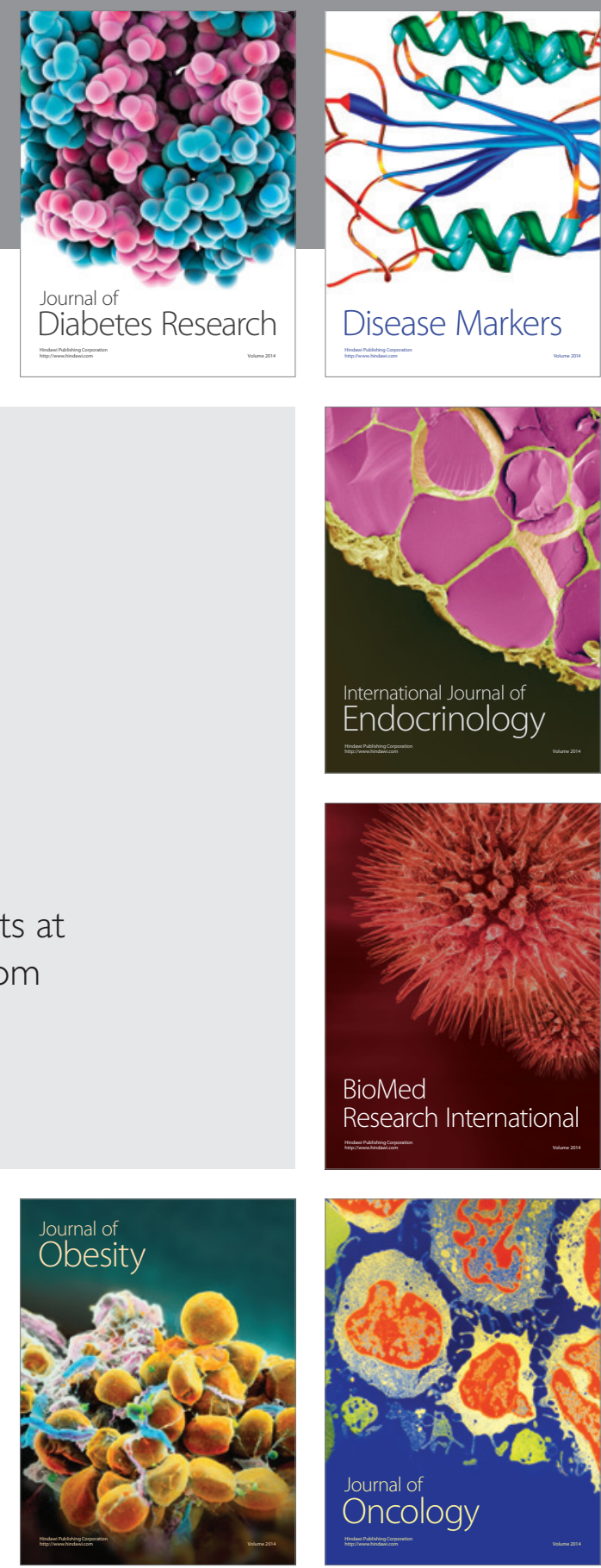

Disease Markers
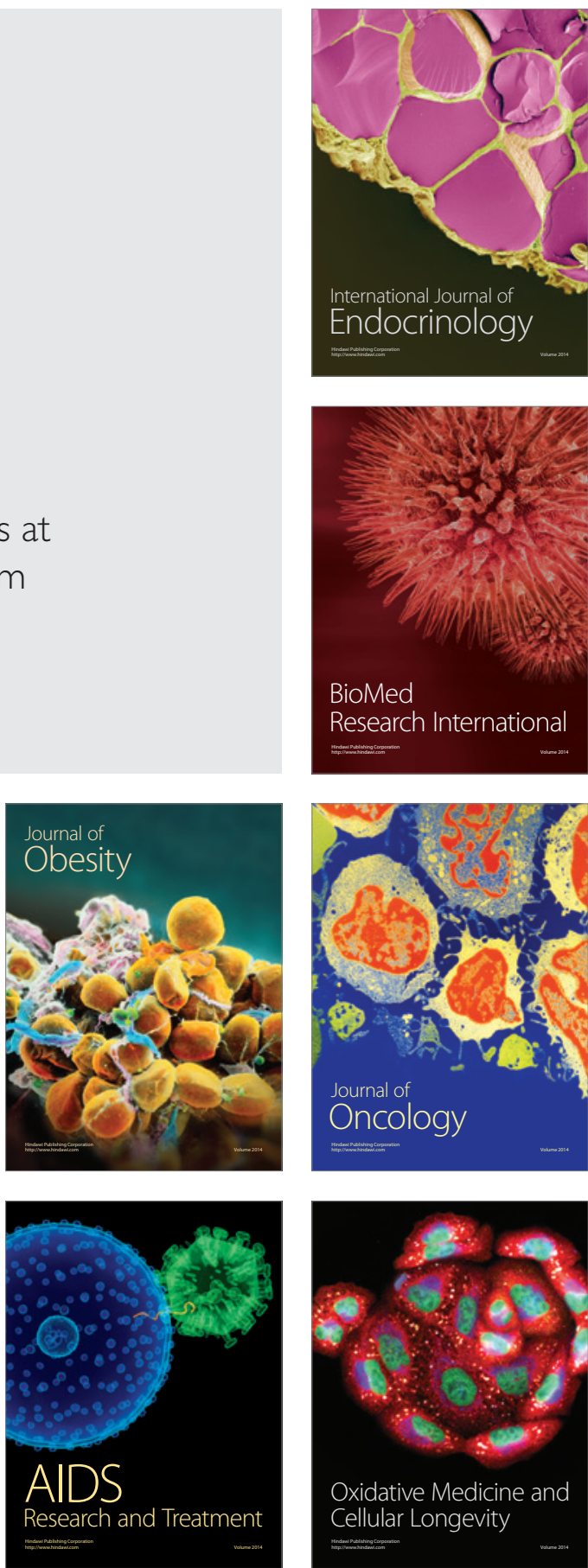